\begin{tabular}{|c|l|}
\hline Title & An A nalysis of Peer Effects on V accination Behavior Using a Model of Privately Provided Public Goods \\
\hline Author(s) & Itaya, Jun-ichi; Ibuka, Y oko; Miy azato, Naomi \\
\hline Citation & Discussion Paper, Series A, 321, 1-42 \\
\hline Issue Date & 2018-02-25 \\
\hline Doc URL & http://hdl.handle.net/2115/68392 \\
\hline Type & bulletin (article) \\
\hline File Information & DPA 321.pdf \\
\hline
\end{tabular}

Instructions for use 
Discussion Paper, Series A, No.2018-321

An Analysis of Peer Effects on Vaccination Behavior Using a Model of Privately Provided Public Goods

\author{
Jun-ichi Itaya \\ Yoko Ibuka \\ Naomi Miyazato
}

February.2018

Faculty of Economics and Business

Hokkaido University

Kita 9 Nishi 7, Kita-Ku, Sapporo 060-0809, JAPAN 


\title{
An Analysis of Peer Effects on Vaccination Behavior Using a Model of Privately Provided Public Goods *
}

\author{
Yoko Ibukał Jun-ichi Itaya ${ }^{\ddagger}$ and Naomi Miyazato ${ }^{\S}$
}

February 25, 2018

\begin{abstract}
Traditional economic models of vaccination behavior simply assume that agents freeride on the vaccination decisions of others. We provide three different models of private provision of a public good, such as a joint production model and a conjectural variation model, to explain how a positive peer effect regarding vaccination behavior arises. We conduct two empirical studies using Japanese data in these models. The first empirical analysis, using a data set on the vaccination behavior of neighbors residing in the same block of a city, finds the existence of positive peer effects on individuals' vaccination decisions. The second empirical analysis also confirms that there are peer effects on the vaccination decisions of members of the same household using a dataset from the national survey we conduct.
\end{abstract}

JEL classification: $\mathrm{H} 41 ; \mathrm{H} 12$

Keywords: Peer effect; Public Good, Vaccination; Free-rider;

${ }^{*}$ We thank Masayoshi Hayshi for his useful comments. The authors gratefully acknowledge financial support provided by a Grant-in-Aid for Scientific Research (B) from the Japan Society for the Promotion of Science (\# 770203).

${ }^{\dagger}$ Faculty of Economics, Keio University, Tokyo 108-8345, Japan. Email: ibuka@econ.keio.ac.jp

$\ddagger$ Corresponding author. Graduate School of Economics and Business Administration, Hokkaido University, Sapporo 060-0809, Japan. Tel: +81-11-706-2858; Fax: +81-11-706-4947; E-mail: itaya@econ.hokudai.ac.jp

${ }^{\S}$ Faculty of Economics, Nihon University, Tokyo 108-8345, Japan. Email: miyazato.naomi@nihon-u.ac.jp 


\section{Introduction}

With the pandemic of new strains of influenza and increased potential risk of bioterrorism, it is important to study infection control measures. Vaccination is an effective measure for infectious diseases. It decreases the probability of infection for both the vaccinated and unvaccinated. The benefit of vaccination is not limited to those who get vaccinated; nor does it decrease when the unvaccinated enjoy the benefit from vaccination. The benefit from vaccination is non-excludable and non-rivalrous and thus, vaccination is a pubic good. Hence, vaccination is an example of voluntary provision of public goods.

The primary prediction from the standard voluntary provided public-good model of Warr (1983) and Bergstrom et al. (1986) is that individuals free-ride on others' contributions. Freeriding behavior usually indicates a negative peer effect. This feature of the standard model is not consistent with considerable empirical findings in various fields of education, workplace and health, most of which, including our own empirical studies, support a positive peer effect. The purpose of this study is to construct alternative theoretical models based on the standard voluntary provision model augmented by introducing either social preference (e.g., Andreoni, 1990; Glazer and Konrad, 1996; Romano and Yildirim, 2001) or a conjectural variations function of other's past contributions in order to explain a positive peer effect in public goods provision (i.e., vaccinating behavior of people), and to test the hypothesis deduced from those theoretical models using two original data sources.

There is extensive literature on a game-theoretic epidemiological model of vaccination choice in conjunction with population dynamics equipped with evolving strategies (e.g., Bauch et al., 2003; Bauch and Earn, 2004; Bauch, 2005; Barrett, 2007 ; Manfredi, et al., 2009; Taisser et al., 2015). The model includes the traditional effects of vaccine choice, in which individuals weigh up the benefits of declining the probability of infection for both self and other individuals versus the costs of vaccination, such as taking the risk of harmful side effects from vaccination. In addition, each individual considers strategic elements of choice related to vaccination. For example, as more individuals become vaccinated, the probability that a non-vaccinated individual is infected deceases, making it less beneficial for the individual to 
be vaccinated, because she has less and less chance that she will herself be infected. In this case, peer effects are non-conforming in the sense that an increase in vaccination coverage by peers leads to a decrease in an individual's probability of getting vaccinated. Conversely, if an individual is surrounded by peers who choose not to be vaccinated, such an individual could face strong peer pressure to conform. In this case, peer effects are conforming such that a decrease in vaccination by peers leads to a decrease in an individual's probability of vaccinating.

In this study, instead of the game theoretic approach mentioned above, we develop a theoretical model based on the standard voluntary public good model of altruistic behavior to explain voluntary vaccination behavior. This altruistic behavior is manifested by the total provision of public goods appearing in the utility function in the standard voluntary provision model of Warr (1983) and Bergstrom et al. (1986) on the ground that vaccination not only protects oneself but also contributes to the herd immunity that benefits others. There are further plausible reasons for using this framework. The first is that the use of utility functions not only enables us to capture the source of generating this effect, but also allows us to easily investigate the impacts of heterogeneous individuals in terms of tastes compared to the game-theoretic model. In particular, heterogeneous preferences play an important role in the vaccinating decisions of household members within a family (see Subsection 3.2 for the empirical study). The second reason is that we want to show how a peer effect on vaccination is related to the individual's tastes; opportunity costs, such as reducing income, his or her own time and effort that could be used to buy private goods, or the price of vaccination, through the individual's budget constraint; and beliefs about the responses of other individuals. By contrast, in most of the game-theoretic epidemiological literature mentioned above, there is no explicit modeling of individuals' choices based on individuals' utility-maximizing behavior, and, instead, those game theoretic models usually assume that individuals act according to pure self-interest by simply comparing the costs of vaccination, including side-effects, with the benefit of reducing morbidity risk, given the total vaccination coverage level. To introduce peer effects, for example, Bodine-Baron et al. (2013) simply add the ad-hoc rewards an individual obtains by conforming to the expected payoffs for the vaccinated and non-vaccinated. 
Nevertheless, it seems unclear how such ad hoc rewards are related to the more fundamental structure of the model, such as preferences. The third is that employing the models of voluntary provision of public goods allows us to utilize the rich results and insights that have emerged in the voluntary provision literature. For example, it is well documented that the private provision of public goods suffers from the free-riding problem owing to the pure public good's characteristics of being non-excludable and non-rivalrous (see, e.g., Ibuka,et al. 2014). More importantly, free-riding behavior of individuals refers to the suboptimality that often characterizes the Nash or non-cooperative equilibrium associated with the provision of a public good, because every individual strategically ignores the externality of benefits arising from the public good, which spills over to others. However, these theoretical findings are not only inconsistent with most of the empirical observations, but also conflict with the empirical findings in this study - that there is certainly a positive or conforming peer effect on vaccination. To resolve these disagreements, more recent studies in the literature, such as Andreoni (1990), Glazer and Konrad (1996), and Romano and Yildirim (2001), have extended the standard voluntary provision model of Warr (1983) and Bergstrom et al. (1986) to models in which utility is derived from not only the consumption of private goods and the total provision of public goods but also from the act of giving such as warm-glow, social status, prestige, signaling for the quality of a public good, and bandwagon effects. The predictions of the extended models are more in line with actual behavior patterns. Moreover, we can show that those extended models make it possible to derive a positive or conforming peer effect.

We employ three different voluntary provision models that have emerged in the literature to explain how positive peer effects arise in individuals' vaccination decisions. The first model we consider is the joint production model suggested by Cornes and Sandler (1984b), Andreoni (1990), and Romano and Yildirim (2001), in which we assume that the desire for social position, avoiding social stigma, or gaining social prestige, enters an individual's utility function as a third factor. Specifically, we consider individuals with a desire for social position who may try to target how much they give based on the average amount of the community or social reference groups, thereby minimizing the deviation of their own contribution from the mean contribution of the community when they have vaccinations. The most common assumption 
on others' behavior is Nash conjectures by which each individual expects no response from the rest of the community to variations in her own contribution. However, unless the reaction curve for the rest of the community is in fact the horizontal, reflecting an actual response of zero, a zero conjecture is not consistent with the observable facts in real life. Hence, the second type of model we consider is the non-Nash conjectural variations models suggested by Cornes and Sandler (1984a), in which individuals who are aware that others respond to changes in their donations form conjectural variations that predict those responses and incorporate such conjectures in their decisions. We show that the conjectural variations model can easily materialize a conforming (or positive) peer effect as long as the conjectural variation function depends positively on the past contributions of others. As a third model, we use the weakeror weakest-link technology of supplying public goods rather than the standard summation supply technology, because the former technology type is more suitable for the description of the role of vaccination in preventing transmission of a disease, which benefits other individuals or social reference groups (see Hirshleifer, 1983).

The role of peer effects has been emphasized in the context of educational outcomes (Angrist and Lang, 2004) based on a body vast of empirical research. Our study is motivated by empirical observations that suggest peers' influence on health behavior. For example, there are intensive studies on risky health behavior, such as drug use, drinking alcohol, and smoking (Gaviria and Raphael, 2001; Kawaguchi, 2004; Powell et al., 2005; Lundborg, 2006; Clark and Loheac, 2007; Eisenberg et al., 2014). With a few exceptions (e.g. , Evans et al., 1992), the results indicate robust positive peer effects. Peer effects are shown not only in the health behavior of individuals, but also in health outcomes, such as BMI (Christakis and Fowler, 2007; Fowler and Christakis, 2008; Trogdon et al., 2008). Finally, two recent papers specifically analyze peer effect in vaccination decisions (Sato and Takasaki, 2016; Rao et al., 2017). Our study is unique in the sense that it provides a theoretical framework in line with public goods provision to explain peer effects.

Technical challenges in estimating peer effects lie in reflection problems (Manski, 1993), which cause a problem in the identification of a causal influence in behavior from one person to another. To deal with this problem, researchers utilize the instrumental variable approach 
(Gaviria and Raphael, 2001; Powell et al., 2005; Trogdon et al., 2008) or a lagged variable in a panel dataset (Clark and Loheac, 2007). Recent research uses a natural experiment (Eisenberg et al., 2014; Dahl et al., 2014). In this study, we use several different methods to handle the reflection problem. Specifically, Study 1 uses a panel dataset with a lagged dependent variable as well as an external shock to change the composition in peers. Study 2 employs a discontinuity in vaccination incentives that arises from the current immunization policy in Japan.

The remainder of the paper is organized as follows. Section 2 provides three different models of private provision of a public good as a theoretical framework to explain positive peer effects. Section 3 presents empirical studies for peer effects using data on Itoman and online survey data on household vaccinating behavior. Section 4 concludes with a discussion of possible extensions of the model. Detailed mathematical derivations are provided in the appendix.

\section{The model}

A common estimated model in the peer effects literature is given in a linear-in-means model. This can be written as

$$
g_{i}=\alpha+\gamma \bar{g}_{-i}+\varepsilon_{i}
$$

where the donation amount given by donor $i, g_{i}$, is estimated as a function of the mean of all past donations, $\bar{g}_{-i}$, and $\varepsilon_{i}$ is an error term. There are well-known problems in identifying peer effects. In this study, we rule out the reflection problem articulated by Manski (1993), as the amount given by individual $i$ does not affect the donations made by previous donors. Specifically, the expectation that is most consistent with observed peer effects is that each individual uses information on other individuals' past vaccinating behavior as a benchmark in deciding whether to have vaccinations. As a result, of particular interest is whether parameter $\gamma$ is positive or not, because $d g_{i} / d \bar{g}_{-i}=\gamma$ represents a peer effect. Using (1), most of the empirical literature confirms that donors respond positively to how much their peers have given in previous periods. We first consider the three theoretical models outlined in 
the introduction to examine how a peer effect arises from each model, and in particular, how a conforming or positive peer effect arises. We show the following: if it is negative, a peer effect could arise from free-riding behavior, which has been well documented in the standard voluntary provision literature (see, e.g., Warr, 1983; Bergstrom et al., 1986); if it is positive, a peer effect arises from different motivations other than a negative free-riding incentive.

\subsection{Joint production model}

We first consider a joint production model of private provision of public goods, as in Cornes and Sandler (1984b) and Romano and Yildirim (2001). There are $n$ individuals indexed by $i=1,2, \ldots, n$. Each individual divides her income between private consumption, $c_{i}$, and contributions toward a pure public good, $G$, denoted by $g_{i}$. The preferences of individual $i$ are given by $u^{i}\left(x_{i}, G, Z_{i}\right)$. The variable $Z_{i}$ stands for an additional private motive for giving, like warm-glow, prestige, signaling a quality of a public good, snob effect, and bandwagon effect (see, e.g., Romano and Yildirim, 2001). To materialize peer effects in a concrete form, we further formulate the variable $Z_{i}$ as follows: ${ }^{1}$

$$
Z_{i}=g_{i}-\bar{g}_{-i}=g_{i}-\frac{\sum_{j \neq i} \bar{g}_{j}}{n-1}
$$

This formulation of $Z_{i}$ reflects the idea that the difference between the size of the own contribution $g_{i}$ and the average level $\bar{g}=\sum_{j \neq i} g_{j} /(n-1)$ of the past contributions of the others captures peers effects. In other words, $Z_{i}$ describes the social position of an individual relative to other individuals in the sense that it can be positively assorted by contributing more to the public good as long as the contributions of the others remain unchanged. However, this model can be viewed as a joint production model in such that the individual contribution $g_{i}$ simultaneously generates a public characteristic $G$ and a private incentive regarding the desire for the social relative position $Z_{i}$.

\footnotetext{
${ }^{1}$ Romano and Yildirim (2001) consider the utility function $u^{i}\left(x_{i}, G, Z_{i}\right)$, which contains the more general function $Z\left(g_{1}, g_{1}, . ., g_{n}\right)$ rather than the variable $Z_{i}$ unlike the present model. Their general function $Z\left(g_{1}, g_{1}, . ., g_{n}\right)$ could encompass the warm-glow, snob effect, or bandwagon effect as a special case. In the present study, such a generation serves only to complicate the analysis. Although our specification might be viewed as a special case in Romano and Yildirim's (2001) model, it would be more appropriate to describe a positive peer effect.
} 
Furthermore, we assume

Assumption 1 The utility functions $u^{i}\left(x_{i}, G, Z_{i}\right)$ of individuals $i=1,2, \ldots, n$ are: $(i)$ strictly increasing, strictly quasi-concave, and twice continuously differential with respect to each argument on $R_{++}^{3} ;(i i)$ it satisfies the Inada conditions: $\lim _{G \rightarrow \infty}\left(\partial u_{i}\left(x_{i}, G\right) / \partial x_{i}\right)=0$, similarly for $G$; and (iii) both $x_{i}$ and $G$ are normal goods for each individual.

Following the literature, individuals are assumed to act simultaneously and non-cooperatively and we use Nash equilibrium as the solution concept. Individual $i$ 's budget constraint is expressed by

$$
x_{i}+g_{i}=m_{i},
$$

where $m_{i}$ is the exogenously given income of individual $i$. To focus on the problem at hand, it is assumed that both the relative price between private consumption and public goods, which is set to unity, and individual income are fixed over time.

Individual $i$ maximizes $u^{i}\left(x_{i}, G, Z_{i}\right)$ by his choice of $x_{i}$ and $g_{i}$ subject to her budget constraint (2) and the non-negativity constraints $x_{i} \geq 0$ and $g_{i} \geq 0$, given the contributions of the others $G_{-i}$ as well as assuming that they are unaffected by their own choices, where, as usual, $G_{-i}$ denotes total contributions by all individuals different from $i$ (which might be called "zero conjectures"). Hence, a Nash equilibrium of the corresponding contribution game played by $n$ individuals is defined as follows:

Definition 1 A Nash equilibrium in this model is a collection of strategies $\left\{\left(x_{i}, g_{i}\right) \in R_{+}^{2} \mid i=1,2, \ldots, n\right\}$ such that $\left(x_{i}, g_{i}\right)$ is a solution for the following problem for $i=1,2, \ldots, n$ :

$$
\begin{gathered}
\max _{x_{i}, g_{i}} u^{i}\left(x_{i}, g_{i}+G_{-i}, Z_{i}\right) \\
\text { s.t. } \quad x_{i}+g_{i}=m_{i}, x_{i} \geq 0 \quad \text { and } g_{i} \geq 0, \\
\text { where } Z_{i}=g_{i}-\bar{g}_{-i}=g_{i}-\frac{\sum_{j \neq i} \bar{g}_{j}}{n-1} .
\end{gathered}
$$


The first-order conditions characterizing an interior solution are

$$
\frac{\partial u^{i}\left(m_{i}-g_{i}, g_{i}+G_{-i}, Z_{i}\right)}{\partial g_{i}}=-\frac{\partial u^{i}}{\partial x_{i}}+\frac{\partial u^{i}}{\partial G}+\frac{\partial u^{i}}{\partial Z_{i}}=0, i=1,2, \ldots, n
$$

Note that the variable $\bar{g}_{-i}$ appearing in the variable $Z_{i}$ has already been determined when each choosing $g_{i}$; consequently, it can be exogenously given from the viewpoint of individual $i$. According to (3), the optimal contribution of individual $i$ should be determined by equating the marginal utility of a one-unit increase in her own consumption with the sum of the own marginal utilities resulting from a one-unit increase in the total provision of public goods and improved social position.

To identify peer effects, we focus on a Nash equilibrium in a two-person economy. Taking the total differentiation of $(3)$ yields

$$
\begin{aligned}
& {\left[\begin{array}{cc}
u_{x x}^{1}+u_{G G}^{1}+u_{Z Z}^{1}+2\left(u_{G Z}^{i}-u_{G x}^{i}-u_{Z x}^{i}\right) & -u_{x G}^{1}+u_{G G}^{1}+u_{Z G}^{1} \\
-u_{x G}^{2}+u_{G G}^{2}+u_{Z G}^{2} & u_{x x}^{2}+u_{G G}^{2}+u_{Z Z}^{2}+2\left(u_{G Z}^{2}-u_{G x}^{2}-u_{Z x}^{2}\right)
\end{array}\right] .} \\
& {\left[\begin{array}{l}
d g_{1} \\
d g_{2}
\end{array}\right]=\left[\begin{array}{c}
\left(-u_{x Z}^{1}+u_{G Z}^{1}+u_{Z Z}^{1}\right) d \bar{g}_{-1} \\
\left(-u_{x Z}^{2}+u_{G Z}^{2}+u_{Z Z}^{2}\right) d \bar{g}_{-2}
\end{array}\right]}
\end{aligned}
$$

where $\bar{g}_{-1} \equiv \bar{g}_{2}, \bar{g}_{-2} \equiv \bar{g}_{1}$. Using Cramer's rule, the peer effects are given by

$$
\begin{gathered}
\frac{d g_{i}}{d \bar{g}_{-i}}=\underbrace{|J|^{-1}}_{(+)} \underbrace{\left[u_{x x}^{-i}+u_{G G}^{-i}+u_{Z Z}^{-i}+2\left(-u_{G x}^{-i}-u_{Z x}^{-i}+u_{Z G}^{-i}\right)\right]}_{(-)}\left(-u_{x Z}^{i}+u_{G Z}^{i}+u_{Z Z}^{i}\right) \gtreqless 0 \\
\text { if and only if }-u_{x Z}^{i}+u_{G Z}^{i}+u_{Z Z}^{i} \lesseqgtr 0, i=1,2,
\end{gathered}
$$

where

$$
|J| \equiv\left|\begin{array}{cc}
u_{x x}^{1}+u_{G G}^{1}+u_{Z Z}^{1}+2\left(-u_{G x}^{1}-u_{Z x}^{1}+u_{Z G}^{1}\right) & -u_{x G}^{1}+u_{G G}^{1}+u_{Z G}^{1} \\
-u_{x G}^{2}+u_{G G}^{2}+u_{Z G}^{2} & u_{x x}^{2}+u_{G G}^{2}+u_{Z Z}^{2}+2\left(-u_{G x}^{2}-u_{Z x}^{2}+u_{Z G}^{2}\right)
\end{array}\right| .
$$

The sign of the denominator $|J|$ is positive owing to the (local) stability assumption of a Nash 
equilibrium (see Appendix). The signs of the terms $u_{x x}^{-i}+u_{G G}^{-i}+u_{Z Z}^{-i}+2\left(-u_{G x}^{-i}-u_{Z x}^{-i}+u_{Z G}^{-i}\right)$, $i=1,2$, are negative owing to the assumption of a quasi-concave utility function. The signs of $-u_{x Z}^{i}+u_{G Z}^{i}+u_{Z Z}^{i}, i=1,2$, are ambiguous in general. The term $-u_{x Z}^{i}+u_{G Z}^{i}+u_{Z Z}^{i}$ represents the total effect of increased social position on the marginal utilities of private consumption, public good consumption, and the desire for social position. An individual's contribution will be increasing in that of others (i.e., $d g_{i} / d \bar{g}_{-i}>0$ ) if she is sufficiently concerned about the private benefit of increased social position that she derives from her own contribution.

To identify the sign of $-u_{x Z}^{i}+u_{G Z}^{i}+u_{Z Z}^{i}$, we have to specify the utility function. Considering $u=x^{\alpha} G^{\beta} Z^{\gamma}$ with $0<\alpha, \beta \leq 1$, we obtain

$$
-u_{x Z}+u_{G Z}+u_{Z Z}=G^{\beta} Z^{\gamma-1} x^{\alpha} \frac{\alpha+\beta+\gamma}{m}(\gamma-1)<0 \text { if } \gamma<1,
$$

where noting $x=\alpha m /(\alpha+\beta+\gamma), G=\beta m /(\alpha+\beta+\gamma)$ and $Z=\gamma m /(\alpha+\beta+\gamma)$, which implies that the peer effect is positive if $\gamma<1$. When $\gamma=1,-u_{x Z}+u_{G Z}+u_{Z Z}=0$, implying that the peer effect in (4) vanishes, whereas when $\gamma>1$, the negative peer effect emerges. On the other hand, when the utility function $u(x, G, Z) \equiv v_{1}(x, G)+v_{2}(Z)$ with $v_{2}^{\prime \prime}(Z) \leq 0$ (i.e., the utility function is separable in $Z$ ), then

$$
-u_{x Z}+u_{G Z}+u_{Z Z}=u_{Z Z} \leq 0
$$

and a positive peer effect in (4) prevails. As the last example, consider the constant elasticity of substitution (CES) utility function $u(x, G, Z) \equiv\left(x^{\rho}+G^{\rho}+Z^{\rho}\right)^{1 / \rho}$ with $\rho \leq 1$. In this case, since

$-u_{x Z}+u_{G Z}+u_{Z Z}=\left(x^{\rho}+G^{\rho}+Z^{\rho}\right)^{(1 / \rho)-2} Z^{\rho-1}(1-\rho)\left[-x^{\rho}\left(\frac{1}{x}+\frac{1}{Z}\right)+G^{\rho}\left(\frac{1}{G}-\frac{1}{Z}\right)\right]<0$

where $u_{x Z}=(1-\rho)\left(x^{\rho}+G^{\rho}+Z^{\rho}\right)^{(1 / \rho)-2} x^{\rho-1} Z^{\rho-1}, u_{x Z}=(1-\rho)\left(x^{\rho}+G^{\rho}+Z^{\rho}\right)^{(1 / \rho)-2} G^{\rho-1} Z^{\rho-1}$, 
$u_{Z Z}=(1-\rho)\left(x^{\rho}+G^{\rho}+Z^{\rho}\right)^{(1 / \rho)-2}\left(Z^{\rho-1}\right)^{2}+\left(x^{\rho}+G^{\rho}+Z^{\rho}\right)^{(1 / \rho)-1}(\rho-1) Z^{\rho-2}$, and

$$
\frac{1}{G}-\frac{1}{Z}=\frac{Z-G}{G Z}=\frac{g_{i}-\bar{g}_{-i}-G}{G Z}<0
$$

the peer effect turns out to be positive. In summary, although whether the peer effect is positive or negative depends critically on the form of the utility functions, it is fair to say that the likelihood of emergence of positive peer effects is increased by additional private benefits arising from his own voluntary provision or social preferences such as the desire for social position. Indeed, without such an additional private incentive (i.e., $u_{x Z}=u_{G Z}=u_{Z Z}=0$ ), the peer effect never arises (i.e., $d g_{i} / d \bar{g}_{-i}=0$ ). The stronger the preference toward social status and the more status can be positively influenced by contributing more than an average person to the provision of public goods, the more likely is the conforming peer effect to emerge.

\subsection{Conjectural variations model}

To derive non-zero conjectural variations rather than Nash conjectures or zero-conjectural variations, we consider the following standard optimizing problem:

$$
\begin{gathered}
\max _{x_{i}, g_{i}, h_{i}} u^{i}\left(x_{i}, g_{i}+G_{-i}\right) \\
\text { s.t. } x_{i}+g_{i}=m_{i}, x_{i} \geq 0 \text { and } g_{i} \geq 0 .
\end{gathered}
$$

Taking into account the fact that maximization is conditional on the conjectured response of the other individuals, the first-order conditions characterizing an interior solution are

$$
\frac{\partial u^{i}}{\partial g_{i}}=-\frac{\partial u^{i}}{\partial x_{i}}+\left[1+b_{i}(\Omega)\right] \frac{\partial u^{i}}{\partial G}=0
$$

According to (6), the optimal contribution of individual $i$ is determined by equating the marginal utility of a one-unit increase in her own consumption with the sum of the own marginal utilities resulting from a one-unit increase in the total provision of public good and the induced amount of contributions conjectured by other individuals (i.e., $\left.b_{i}(\Omega) \equiv \partial G_{-i}^{e} / \partial g_{i}\right)$. 
There are many ways of formulating the conjectural variation function $b_{i}(\Omega)$, where $\Omega$ stands for the set of information that influences her beliefs regarding the others' responses. Cornes and Sandler (1984a) formulate conjectural variations as either a positive or negative constant term which is exogenously given or a function of the individual's share of the total provision (which may reflect a bandwagon effect), and further point out that conjectural variations might depend on various factors, such as the total amount of public goods, the contributing amount of social reference groups, the community size, the social norms, and tax system. To derive the peer effect explicitly, we here assume that the conjectural variations function depends on the observations of past contributions made by others:

$$
b_{i}(\Omega) \equiv b_{i}\left(\bar{g}_{-i}\right) \text { with } d b_{i} / d \bar{g}_{-i}>0 \text {. }
$$

Note that the conjectural variations function (7) is different from the original one suggested by Cornes and Sandler (1984a) in that the latter depends on current contributions made by others because of the simultaneous choices of every potential contributor.

Considering a conjectural variation equilibrium in a two-person economy and taking the total differentiation of (6), we obtain the following system of equations in matrix form:

$$
\begin{gathered}
{\left[\begin{array}{cc}
u_{x x}^{1}-u_{x G}^{1}+\left(1+b_{1}\right)\left(u_{G G}^{1}-u_{G x}^{1}\right) & -u_{x G}^{1}+\left(1+b_{1}\right) u_{G G}^{1} \\
-u_{x G}^{2}+\left(1+b_{2}\right) u_{G G}^{2} & u_{x x}^{2}-u_{x G}^{2}+\left(1+b_{2}\right)\left(u_{G G}^{2}-u_{G x}^{2}\right)
\end{array}\right]} \\
{\left[\begin{array}{c}
d g_{1} \\
d g_{2}
\end{array}\right]=\left[\begin{array}{c}
-u_{G}^{1}\left(\partial b_{1} / \partial \bar{g}_{-1}\right) d \bar{g}_{2} \\
-u_{G}^{2}\left(\partial b_{2} / \partial \bar{g}_{-2}\right) d \bar{g}_{1}
\end{array}\right] .}
\end{gathered}
$$

Employing Cramer's rule, the peer effect can be obtained as follows:

$$
\begin{aligned}
& \frac{d g_{1}}{d \bar{g}_{2}}=-\underbrace{|H|^{-1}}_{(+)} \underbrace{\left[u_{x x}^{2}-u_{x G}^{2}+\left(1+b_{2}\right)\left(u_{G G}^{2}-u_{G x}^{2}\right)\right]}_{(-)} u_{G}^{1} \underbrace{\frac{\partial b_{1}}{\partial \bar{g}_{-1}}}_{(+)}>0, \\
& \frac{d g_{2}}{d \bar{g}_{1}}=-\underbrace{|H|^{-1}}_{(+)} \underbrace{\left[u_{x x}^{1}-u_{x G}^{1}+\left(1+b_{1}\right)\left(u_{G G}^{1}-u_{G x}^{1}\right)\right]}_{(-)} u_{G}^{2} \underbrace{\frac{\partial b_{2}}{\partial \bar{g}_{-2}}}_{(+)}>0,
\end{aligned}
$$


where $\bar{g}_{-1} \equiv \bar{g}_{2}, \bar{g}_{-2} \equiv \bar{g}_{1}$ and

$$
|H|=\left|\begin{array}{cc}
u_{x x}^{1}-u_{x G}^{1}+\left(1+b_{1}\right)\left(u_{G G}^{1}-u_{G x}^{1}\right) & -u_{x G}^{1}+\left(1+b_{1}\right) u_{G G}^{1} \\
-u_{x G}^{2}+\left(1+b_{2}\right) u_{G G}^{2} & u_{x x}^{2}-u_{x G}^{2}+\left(1+b_{2}\right)\left(u_{G G}^{2}-u_{G x}^{2}\right)
\end{array}\right| .
$$

The denominator $|H|$ is positive owing to the stability condition of a Nash (non-zero conjectural variation) equilibrium, ${ }^{2}$ while the signs of the terms $u_{x x}^{i}-u_{x G}^{i}+\left(1+b_{i}\right)\left(u_{G G}^{i}-u_{G x}^{i}\right)$, $i=1,2$, are negative owing to the second-order condition and $\left(\partial b_{i} / \partial \bar{g}_{-i}\right)>0$, by assumption. Taken together, the numerators in (8) and (9) are negative. As a result, the peer effects in (8) and (9), respectively, turn out to be unambiguously positive.

Alternatively, we may assume that the conjectural variations of each individual depend positively on the other's share of total contribution in previous periods, i.e., $b_{i}(\Omega) \equiv b_{i}\left(\bar{g}_{-i} / \bar{G}\right)$. In this case, we can obtain a positive peer effect as follows:

$$
\begin{aligned}
& \frac{d g_{1}}{d \bar{g}_{2}}=-\underbrace{|\hat{J}|^{-1}}_{(+)} \underbrace{\left[u_{x x}^{2}-u_{x G}^{2}+\left(1+b_{2}\right)\left(u_{G G}^{2}-u_{G x}^{2}\right)\right]}_{(-)} u_{G}^{1} \frac{\bar{g}_{2}}{\bar{G}^{2}}>0 \text {, and } \\
& \frac{d g_{2}}{d \bar{g}_{1}}=-\underbrace{|\hat{J}|^{-1}}_{(+)} \underbrace{\left[u_{x x}^{1}-u_{x G}^{1}+\left(1+b_{1}\right)\left(u_{G G}^{1}-u_{G x}^{1}\right)\right]}_{(-)} u_{G}^{2} \frac{\bar{g}_{1}}{\bar{G}^{2}}>0 .
\end{aligned}
$$

On the other hand, Sugden (1985) criticizes the arbitrariness of such conjectural variations, because there is neither obvious reason nor a rational way to choose a particular form of exogenously given conjectural variation functions. Moreover, an individual would experiment by making small changes in his own contribution, so that the presence of a non-zero response would in time be revealed to him. A rational individual would learn from such an experience and revise her conjectures concerning the responses of others in the appropriate direction. Sugden (1985) suggests consistent (rational) conjectural variations as the limiting or long-run outcome of such a learning process. ${ }^{3}$ To derive the consistent conjectural variations in the present two-person economy, we first obtain the actual reaction of individual $j$ in response to

\footnotetext{
${ }^{2}$ The stability condition for a Nash equilibrium in the conjectural variation model could be derived in the way outlined in the Appendix.

${ }^{3}$ Furthermore, Sugden (1985) finds that the consistent conjectural variations are always negative under the normality assumptions on private and public goods consumption. Since negative conjectures would not be consistent with real-life examples, he casts doubt on the validity of the utility-maximization approach itself.
} 
the exogenous change in $d \bar{g}_{i}, i \neq j$, denoted by $\left(\partial g_{j} / \partial g_{i}\right)^{a}$, which can be derived from the first-order condition of individual $j:^{4}$

$$
\left(\frac{\partial g_{j}}{\partial \bar{g}_{i}}\right)^{a}=\frac{u_{G G}^{j}\left(1+b_{j}\right)-u_{x G}^{j}}{u_{x G}^{j}-u_{x x}^{j}-\left(1+b_{j}\right)\left(u_{G G}^{j}-u_{x G}^{j}\right)}, i, j=1,2 ; i \neq j .
$$

Since the consistent conjectural variation $b_{i}\left(\equiv\left(\partial g_{j} / \partial g_{i}\right)^{e}\right)$ formed by individual $i$ should coincide with the actual response of the other individual, that is,$\left(\partial g_{j} / \partial g_{i}\right)^{a}$ (see Scafuri, 1988), we obtain

$$
b_{i}=\frac{u_{G G}^{j}\left(1+b_{j}\right)-u_{x G}^{j}}{u_{x G}^{j}-u_{x x}^{j}-\left(1+b_{j}\right)\left(u_{G G}^{j}-u_{x G}^{j}\right)}, i, j=1,2 ; i \neq j .
$$

Assuming symmetric individuals (i.e., $b_{i}=b_{j}$ ), the above expression can be rewritten as

$$
(1+b)\left(u_{G G}-u_{x G}\right)=-b u_{x x}-b(1+b)\left(u_{G G}-u_{x G}\right) .
$$

Assuming the utility function $u=x^{\rho}+G^{\rho}$ with $\rho \leq 1$, the above condition can be reduced to

$$
\frac{b}{(1+b)^{2}}=-\frac{u_{G G}}{u_{x x}}=-\frac{\rho(\rho-1) G^{\rho-2}}{\rho(\rho-1) x^{\rho-2}}=-\left(\frac{\bar{G}}{\bar{x}}\right)^{\rho-2}
$$

where $x$ and $G$ could be considered as the average value of past observations. Let us rewrite the above expression as follows:

$$
b=-A(1+b)^{2}
$$

where $A \equiv(\bar{G} / \bar{x})^{\rho-2}$. Solving the above quadratic equation for $b$ yields

$$
b=-1-\frac{1}{2 A}+\frac{1}{2 A} \sqrt{4 A+1}=-1-\frac{1}{2 A}+\sqrt{\frac{1}{A}+\frac{1}{4 A^{2}}}<0
$$

where a solution that is less than minus one should be ruled out. Therefore, the peer effect is

\footnotetext{
${ }^{4}$ Following Suguden (1985), when identifying the consistent conjectural variations, we need to allow for simultaneous changes in the contributions of all individuals. Instead, we assume that the consistent conjectural variations have been formed as the long-run average outcome resuitng from the learning process as to the actual responses of other individuals. Based on this reasoning, the present conjectural variations model could be viewed as a short-run or temporary equilibrium model, taking the consistent conjectural variations function as given.
} 
given by

$$
\frac{\partial b}{\partial \bar{g}_{-i}}=\frac{1}{2 A^{2}}\left(\frac{1}{A}+\frac{1}{4 A^{2}}\right)^{-\frac{1}{2}} \underbrace{\left[\left(\frac{1}{A}+\frac{1}{4 A^{2}}\right)^{\frac{1}{2}}-\left(1+\frac{1}{2 A}\right)\right]}_{(-)} \underbrace{\frac{d A}{d g_{-i}}}_{(+)}<0
$$

where

$$
\frac{d A}{d \bar{g}_{-i}}=-(\rho-2)\left(\frac{\bar{G}}{\bar{x}}\right)^{\rho-3} \frac{1}{\bar{x}}>0 \text { because } \rho \leq 1 .
$$

By combining (12) with (8) and (9), the peer effect turns out to be negative under the consistent conjectural variations derived from the CES utility function. ${ }^{5}$ The increased previous contributions of other individuals make the consistent conjectures more negative, which in turn leads to a decrease in the contribution of individual $i$; consequently, the consistent conjectural variation is more likely to generate a negative or non-conforming peer effect.

\subsection{Sequential contribution and weaker- or weakest-link supply tech- nology}

Varian (1990) considers a private provision model in which two individuals sequentially choose voluntary contributions to a public good. In this sort of "Stackelberg contribution game," the timing of decisions is that individual 1 (the leader) chooses first, anticipating the best response of individual 2 (the follower). Single-shot, simultaneous-move games cannot provide an adequate description of peer effects, because no individual has any chance of observing the action of other individuals, while in the Stackelberg contribution game, the follower can observe contributions made by the leader and thus, the follower can form the belief (i.e., a peer effect) of the action taken by the leader.

To derive the reaction function for individual 2 (the follower), we first consider the following

\footnotetext{
${ }^{5}$ Sugden (1985) shows that under the general quasi-concave utility function coupled with the assumption of normal goods, the consistent conjectural variation is always negative. On the other hand, Dasgupta and Itaya (1995) derive a consistent conjectural variation in a heterogeneous agent model of voluntary contribution under Cobb-Douglas utility functions. The consistent conjectural variation term appearing in their model turns out to be negative and constant, independently of an individual's contribution as well as the total contribution of a public good.
} 
optimization problem of 2 , given the contribution made by $1, \bar{g}_{1}$ :

$$
\begin{gathered}
\max _{x_{2}, g_{2}} u^{2}\left(x_{2}, \bar{g}_{1}+g_{2}\right) \\
\text { s.t. } x_{2}+g_{2}=m_{2}, x_{2} \geq 0 \text { and } g_{2} \geq 0 .
\end{gathered}
$$

To derive the peer effect, we focus only on the behavior of individual 2 , because she has the opportunity to observe the action of individual 1 (i.e., the leader), so that 2 is in a position of forming the peer effect (i.e., $\partial g_{1} / \partial \bar{g}_{2}$ ) based on the observed action taken by 1 . Take total differentiation of the first-order condition for individual $2, u_{x}^{2}\left(m_{2}-g_{2}, \bar{g}_{1}+g_{2}\right)=$ $u_{G}^{2}\left(m_{2}-g_{2}, \bar{g}_{1}+g_{2}\right)$, to yield

$$
\frac{d g_{2}}{d \bar{g}_{1}}=\frac{-u_{x G}^{2}+u_{G G}^{2}}{-u_{x x}^{2}+u_{x G}^{2}+u_{G x}^{2}-u_{G G}^{2}}<0
$$

because $-u_{x G}^{2}+u_{G G}^{2}<0$ due to the normality assumption of private consumption and $-u_{x x}^{2}+$ $u_{x G}^{2}+u_{G x}^{2}-u_{G G}^{2}>0$ due to the second-order condition. This result is consistent with the finding of Varian (1994) that under sequential moves, a first-mover enjoys a first-mover advantage by contributing zero, relying on other contributors to provide a positive amount of the public good. Moreover, it is possible that the higher valuation agent moves first and eventually contributes zero, and the lower valuation agent then contributes his individually optimal level so that the public good is provided at even a lower level. Hence, it is fair to say that sequential contribution may aggravate the free-rider problem, so that the peer effect unambiguously becomes negative. In other words, to generate a positive peer effect, an additional private incentive or social norm to conform, which may be captured by $Z$ in the joint production model, is needed to overcome the free-riding tendency of individuals in addition to an altruism motivation or the benefit of the public good that spills over to other individuals.

The association between individual contributions and the total amount of the public good is known as the summation technology of public goods (i.e., $G=\sum_{j=1}^{n} g_{j}$ ), which has been assumed so for. Such a summation technology is usually associated with undersupply of a 
public good, because contributors care only about their own additional benefits relative to the additional costs when determining how much to contribute. Here, we consider weakerlink supply technology, such as $G=\left[\left(g_{1}\right)^{\rho}+\left(g_{2}\right)^{\rho}\right]^{1 / \rho}$ in the Stackelberg contribution game presented earlier in this subsection. The first-order condition is given by

$$
u_{x}^{2}\left(m_{2}-g_{2}, G\right)=u_{G}^{2}\left(m_{2}-g_{2}, G\right)\left[\left(\bar{g}_{1}\right)^{\rho}+\left(g_{2}\right)^{\rho}\right]^{(1 / \rho)-1}\left(g_{1}\right)^{\rho-1},
$$

noting that $\bar{g}_{1}$ has been previously chosen by individual 1 (i.e., the leader). To derive the peer effect, we further assume $u^{2}\left(x_{2}, G\right) \equiv x_{2} G$. By substitution, we obtain the first-order condition for an interior solution, $G=\left(m_{2}-g_{2}\right)\left[\left(\bar{g}_{1}\right)^{\rho}+\left(g_{2}\right)^{\rho}\right]^{(1 / \rho)-1}\left(\bar{g}_{1}\right)^{\rho-1}$, which can be rewritten as

$$
\left(\bar{g}_{1}\right)^{\rho}+\left(g_{2}\right)^{\rho}=\left(m_{2}-g_{2}\right)\left(\bar{g}_{1}\right)^{\rho-1} .
$$

Totally differentiating and rearranging the above expression yields

$$
\frac{d g_{2}}{d \bar{g}_{1}}=\frac{-\rho+\left(m_{2}-g_{2}\right)(\rho-1) / \bar{g}_{1}}{\rho\left(g_{2} / \bar{g}_{1}\right)^{\rho-1}+1}<0 \text { for }-\infty<\rho<1,
$$

with

$$
\frac{d g_{2}}{d \bar{g}_{1}}=-\frac{1}{2}<0 \text { for } \rho=1 \text { and } \frac{d g_{2}}{d \bar{g}_{1}}=-\left(m_{2}-g_{2}\right)<0 \text { for } \rho=0
$$

Hence, the peer effect on vaccination turns out to be negative; thus, the situation does not change.

Vaccination forestalls the spread of a disease, so that it may be best described by the weakest-link technology, $G=\min \left\{g_{1}, g_{2}\right\}$. In this case, whether or not the peer effect appears hinges on who becomes the least contributor. Suppose that the least contributor is individual 1, implying that $\bar{g}_{1}=\min \left\{\bar{g}_{1}, \bar{g}_{2}\right\}$. When individual 1 (i.e., the leader) increases her contribution, individual 2 (i.e., the follower), observing her behavior, is willing to increase $g_{2}$. In this case, we obtain $d g_{2} / d \bar{g}_{1}=1>0$. On the contrary, when individual 1 , who is not the least contributor, increases her own contribution, there is no incentive for individual 2 to increase his contribution. Hence, in this case $d g_{2} / d \bar{g}_{1}=0$, and thus, the positive peer effect does not emerge. Weakest-link technologies are invariably associated with an assurance game, in 
which at the equilibria, players match one another's contribution, because there is no gain, only costs, from exceeding the minimal contributions. Only when the least donor contributes more public good in the previous period, does the other individual have much to gain by also contributing the same amount, so that positive benefits will be achieved. In summary, the positive or conforming peer effect will emerge only when the first-move donor is the smallest one.

\section{Data and Methods}

To empirically examine peer effects in vaccination decisions, we conduct two analyses, Study 1 and Study 2, using two unique data sources. The two studies differ in the definition of peers, age of the study participants, and identification strategies and we use them supplementally. Study 1 analyzes peer effects with geographical units as peers. Specifically, we use a unit of town blocks called "Aza," ("township" in Japanese) in Okinawa prefecture, a group of islands located at the southernmost point of Japan. We obtain administrative data of vaccination status among those aged 65 years and above with physical addresses from the municipal government to examine the impact of vaccination status of other individuals (i.e., peers) in the same Aza on the individuals' decisions on whether or not to get vaccinated. In addition, we use an alternative definition of peers, namely, household members. This definition of peers is thought of as being tighter and more influential for vaccination decisions, and thus, we

utilize members leaving households as an exogenous shock for peer effects. Study 2 uses a dataset from an original online survey we conducted in 2014. In Study 2, we define household members as peers. The online survey approximates the population both in terms of age and regional distribution. We describe the data and methods of each study in greater detail in the following subsections.

\subsection{Institutional Background}

In the current study, we investigate peer effects on vaccination behavior using two original datasets from the Japanese population. Here, we provide a brief overview of the institutional 
background regarding immunization policies in Japan. Japan has provided universal health insurance coverage since 1961, whose benefits cover healthcare for treatment but not for prevention. Thus, as vaccination is part of preventive care, it is not covered by the national health insurance. Instead, under the national immunization program, the government provides subsidies for the costs of vaccination for some targeted diseases. Since 2001, influenza vaccination has been one of the diseases targeted by the program, and the costs of influenza vaccination have been subsidized by the government. However, the population covered by the subsidies is limited to those aged 65 years or above, and those aged between 60 and 64 years with certain chronic conditions. Other diseases targeted by the program include diphtheria, pertussis, polio, measles, and rubella. In this study, we examine the peer effects in decision-making on vaccination against influenza. There are at least two reasons we focus on this particular disease for our analysis: first, under the Japanese national immunization program, influenza vaccination is unique in the sense that the eligibility for subsidies depends on individual's age. The age-dependent eligibility creates discontinuity in financial incentives to receive vaccination, which we utilize for the identification of peer effects. Second, immunity of influenza vaccination lasts for less than 1 year, and individuals should be vaccinated every year, unlike most of the diseases for which vaccination is available. The characteristics of vaccination together with our panel dataset enables us to analyze vaccination behavior controlling for time invariant factors, such as time and risk preferences, which are considered important factors for vaccination decisions (Chapman and Coups , 1999; Nuscheler and Roeder, 2015).

\subsection{Study 1: An analysis using administrative data from Itoman city, Okinawa}

\subsubsection{Data}

We use the administration data of influenza vaccination status among individuals aged 65 years or above in Itoman city, Okinawa prefecture. Itoman city is located on the largest island of Okinawa prefecture, the so-called main island, and had a population of 60,714 at the end of fiscal year 2016. The population of those aged 65 years or above numbered 11,728 at the end 
of fiscal year 2016. We conduct two empirical analyses using the datasets. In the first analysis, we define geographical units as peers and employ panel data analyses with a lagged variable. Figure 1 shows a residential map of those aged 65 years and over in Itoman city. Itoman city has 51 townships. Residences are scattered around the city, and the distinction of each township is clear, making the city ideal for our analysis of peer effects. We define residents in the same township as peers in Study 1. In the second analysis, we define household members as peers and examine how the probability of vaccination changes when a member disappears from the household.

Under Japan's national immunization program, each municipality is responsible for providing citizens with vaccination at the appropriate times, and the municipal government keeps a record of the vaccination status of all the targeted individuals. The targets of influenza vaccination are restricted to those aged 65 years and above and some aged between 60 and 64 years. Our dataset includes information on influenza vaccination status of all citizens aged 65 years and above in Itoman city. In addition, the data include information about physical address, age, and sex. We use the record of vaccination status as the dependent variable. The variable is unity if an individual gets vaccinated and zero otherwise. The dataset is panel data from the fiscal years 2011 to 2013. Each fiscal year runs from April to March of the next year.

Table 1 shows descriptive statistics. The average vaccination rate is $63.3 \%$. The age of individuals ranges from 59 to 107 years old with a mean age of 76 years. The average population of an Aza is 314, and the average number of hospitals within a radius of 500 meters of an individual's home is less than one. Of the sample of residents, $1 \%$ have experienced the disappearance of a cohabiter from the home.

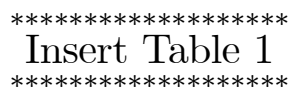

\subsubsection{Empirical Specification}

In the first analysis, we consider township members as peers. As the main outcome, $g_{i, j, t}^{*}$, is a binary to indicate whether an individual $i$ in the township $j$ got vaccinated in year $t$, we use a probit model with panel data to examine the peer effect using the following specification: 


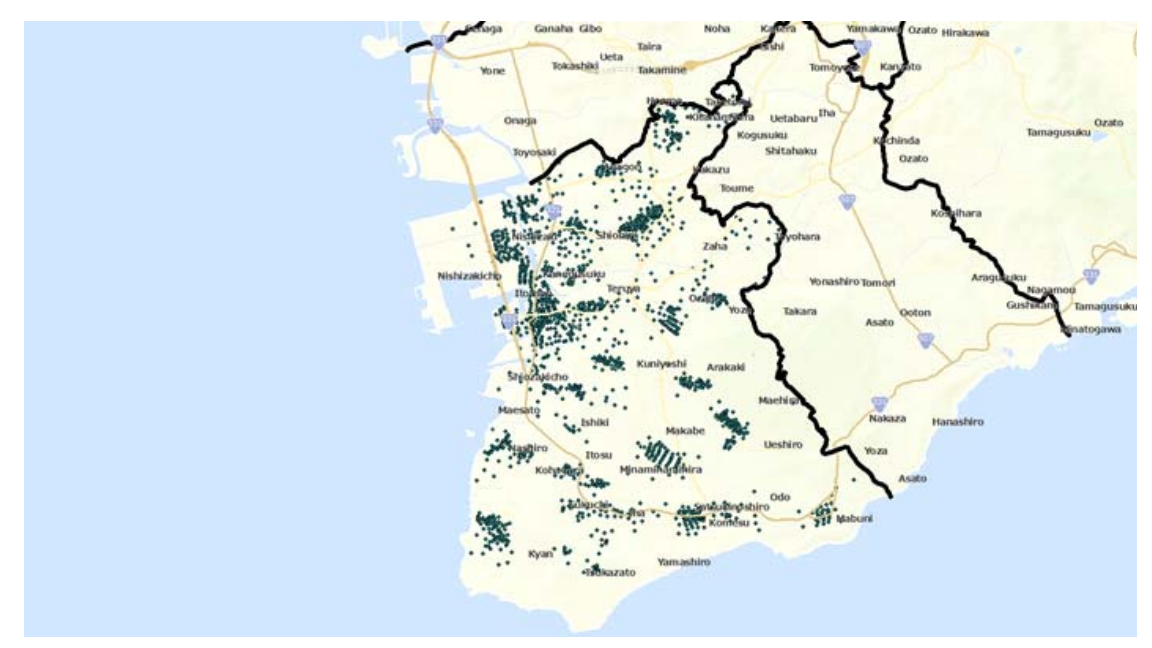

Figure 1: Map of Itoman-city: Each dot shows the location of residence of individuals aged 65 years and above.

$$
\begin{gathered}
g_{i, j, t}^{*}=\phi\left(\theta Z_{-i, j, t-1}+\beta x_{i, t}+\gamma w_{j, t}+\varepsilon_{i, t}\right), \\
g_{i, j, t}=\left\{\begin{array}{c}
1 \text { if } g_{i, j, t}^{*}>0, \\
0 \text { if } g_{i, j, t}^{*} \leq 0,
\end{array}\right.
\end{gathered}
$$

where $Z_{-i, j, t-1}$ is a variable of peers indicating the vaccination rate within each township. We divide the number of those who got vaccinated in the township by the number of residents aged 65 years and above in the same township both excluding self to calculate the observed vaccination rates of the peers. Thus, the vaccination rate is calculated as $Z_{-i, j, t-1}=$ $\sum g_{-i, j, t-1} / \sum n_{-i, j, t-1}$, where $g_{-i, j, t-1}$ is the number of people who got vaccinated in township $j$ excluding individual $i$ in year $t-1$, and $n_{-i, j, t-1}$ is the number of residents in township $j$, again excluding individual $i$. Thus, $\theta$ is our coefficient interest. $x_{i}$ is a column vector that includes a set of control variables at the individual level, and $\beta$ is a row vector for the control variables. $w_{j}$ is a column vector that includes a set of control variables at the Aza level, and $\gamma$ is a row vector for corresponding coefficients. $\varepsilon_{i}$ is an error term. We use different estimation methods to make an inference on $\theta$ to take advantage of the panel structure of the dataset. First, we use a pooled probit model. Next, we use a random-effect probit model. However, in terms of fixed effects, a probit estimator is known to suffer from the incidental parameter problem. Thus, we employ a linear probability model when we control for an individual fixed 
effect. $^{6}$

As for the control variables, we include both individual and township characteristics. Individual characteristics include sex, age, and age squared of individuals, while township characteristics include population size, average age, and the ratio of females to total residents which are calculated using our dataset with those aged 65 years and above. Furthermore, we include the number of hospitals within a radius of 500 meters of an individual's home in order to control for medical resources.

To handle a reflection problem, we use two alternative approaches to address the problem. First, we use neighborhood vaccination rates in the previous period, where the variable of peers is set as $Z_{-i, j, t-1}$. While an individual's own vaccination behavior could potentially affect that of neighbors in the same period, it cannot affect the neighbor's behavior in the previous period, following Clark and Loheac (2007). Second, we use an exogenous shock to change the composition of cohabiters when we conduct the analysis with peers as household members in the second analysis. Specifically, from the dataset, we can detect cohabiters' loss from a household. As we have information on individuals' physical addresses, we identify cohabiters' who move out of their homes. We investigate the effect of an exogenous change on the probability of vaccination. We estimate the effect of the exogenous shock on an individual's probability of vaccination. Thus, we estimate the following reduced-form equation:

$$
\begin{gathered}
g_{i, t}^{*}=\varphi\left(\theta \text { Event }_{-i, t}+\beta x_{i, t}+\gamma w_{j, t}+\varepsilon_{i . t}\right), \\
g_{i, t}=\left\{\begin{array}{l}
1 \text { if } g_{i, t}^{*}>0, \\
0 \text { if } g_{i, t}^{*} \leq 0,
\end{array}\right.
\end{gathered}
$$

where Event $_{-i, t}$ is a variable to capture the shock to decrease the number of household members between $t-1$ and $t$, and takes unity if the individual experiences such an event and zero otherwise. For this analysis, we restrict the sample to only households with two people in the first year of our analysis. If an individual experiences a loss of a household member, we

\footnotetext{
${ }^{6}$ Instead of a linear probability model, it is possible to employ a logit model with fixed effect. However, in the case of the logit model, only the observations for individuals who switched vaccination status are used in the estimation. Many observations in our dataset are dropped if we employ the logit model with fixed effect. Thus, we employ the liner probability model with fixed effect.
} 
expect that the probability of vaccination would decline. Thus, the coefficient of the event is expected to take a negative sign in the existence of positive peer effects.

\subsubsection{Results}

Table 2 shows the estimation results for household members as peers. In the probit regression with pooled data, the coefficient of peer effects is positive and statistically significant, indicating that an increase in the probability of neighborhood vaccination induces an increase in the probability of vaccination (Column(1)). The coefficients of age and age squared show a statistically significant effect, indicating a non-linear effect of age on the probability of vaccination. The results using random- and fixed-effect models (Columns (2) to (4), respectively) confirm that neighborhood vaccination increases the probability of an individual's vaccination when we control for unobservable heterogeneity.

Insert Table 2

$* * * * * * * * * * * * * * * * * * *$

Next, we use an exogenous shock to deal with the reflection problem. Columns (1) and (2) in Table 3 show the results from the random-effect model and Column (3) in the same table shows the result from the fixed-effect model. The coefficients of the loss of household members are negative and statistically significant, indicating that the probability of vaccination decreases following the loss of a cohabiter. To further examine whether the effect remains unchanged when we restrict our samples to those vaccinated before they left home, we perform additional regressions in the restricted samples (Table 4). The coefficients of loss of household members are negative and statistically significant, suggesting positive peer effects. Furthermore, we add an interaction term between the variable of loss of household members and the variable of township vaccination rate in period $t-1$ to investigate if the peer effect from household members is mitigated by the peer effects from neighbors (Table 5). The coefficient of an interaction term in the fixed-effect model in Column (3) is positive and statistically significant, indicating that a decline in the probability of vaccination owing to a loss of household 
members is mitigated when peer effects from neighbors are high.

Insert Tables 3 to 5

$* * * * * * * * * * * * * * * * * * * * * * * * * * * * *$

\subsection{Study 2: An analysis using discontinuity approach with an on- line survey}

\subsubsection{Data}

We conducted an online survey in September 2014 via a commercial survey company. The survey invitation was sent to the registered individuals and those who received and agreed to participate in the survey proceeded to the online questionnaire directed by the invitation. A total of 1,585 invitations were sent and 1,000 respondents completed the survey. The response rate is $63.1 \%$.

The definition of "peer" in this study is individuals with whom each respondent lives in the same household. Our identification strategy is to take advantage of a discontinuity in the out-of-pocket payment of vaccination costs determined by peers' age. As explained in Subsection 3.1, a subsidy for vaccination against influenza starts at the age of 65 years under Japan's national immunization program. Thus, a vast majority of those aged under 65 years pays vaccination costs out of pocket whereas those aged 65 years and above receive a subsidy for vaccination. As a result, those aged 65 years and above are more likely to get vaccinated than are those aged under 65 years (Kondo et al., 2004; Ibuka and Bessho, 2015 ). In the survey, we recruit two types of individuals aged under 65 years as respondents: those who live with only individuals under aged 65 years and those who live with individuals aged 65 years and above. In this setting, we can consider peers' age as a running variable. The age of 65 years is a convention marker rather than a clinical fact that affects the risk of influenza infection, and there is no major change in policies at that particular age that could potentially affect individuals' vaccination behavior besides the subsidy program under the immunization program. Consequently, an increase in peers' vaccination uptake at 65 years of age could be considered the peer effect. 
The survey questionnaire asked about vaccination status as well as other questions regarding socioeconomic and health status of the respondents and other household members who are likely to influence individuals' vaccination decisions. The key question, which we use as the dependent variable, is whether a respondent was vaccinated in the previous influenza season, that is, during the 2013-2014 influenza season. In addition, the survey asked the age of all household members and their vaccination status in the same season. We use this information as a key dependent variable.

Table 6 presents the descriptive statistics of the survey. Out of 1,000 respondents of the survey, 100 were aged 65 years and older. Our analysis focuses on the rest, that is, 900 individuals aged under 65 years. The vaccination rate among the respondents is $30 \%$, and approximately half the respondents had at least one person aged 65 years or above as a household member whereas the rest lived with cohabiters aged under 65 years. Among household members, excluding the respondents themselves, $27 \%$ were vaccinated.

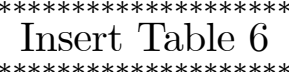

\subsubsection{Empirical Specification}

As the main outcome is a binary to indicate whether a respondent $i$ got vaccinated in the 2013-2014 influenza season, we use a standard probit model to examine the peer effect using the following specification:

$$
\begin{gathered}
g_{i}^{*}=\phi\left(\theta Z_{i}+\beta x_{i}+\varepsilon_{i}\right), \\
g_{i}=\left\{\begin{array}{l}
1 \text { if } g_{i}^{*}>0, \\
0 \text { if } g_{i}^{*} \leq 0,
\end{array}\right.
\end{gathered}
$$

where $Z_{i}$ is a binary that takes unity if a respondent $i$ is in the treatment group, that is, has at least one household member aged 65 years or above, and zero otherwise. As we identify a causal peer effect from a household member of a respondent who is 65 years old or above to the respondent under 65 years old, $\theta$ is the coefficient of our interest. $x_{i}$ is a column vector 
that includes a set of control variables, and $\beta$ is a row vector for the control variables. $\varepsilon_{i}$ is an error term.

As for the control variables, we include the respondents' characteristics as well as their household characteristics that could potentially influence their vaccination decisions. Respondents' socioeconomic variables include sex, age, age squared, education level (reference group: college degree), and working status. In addition, as an independent variable we add the number of influenza shots in the past 5 years to control for an individual's preferences for vaccination. We also include four binaries to indicate perceived health status of individuals. Furthermore, we include a set of characteristics of a respondent's household, which is particularly important, as our strategy relies on the characteristics of households, that is, the existence of those 65 years and older, to identify the positive peer effect. The household characteristics include household size, a binary to indicate if the household has at least one child aged under 6 years, the number of children under 6 years, and the maximum, minimum, and average ages of household members, excluding the respondent. We run regressions both with and without household income as an independent variable owing to the non-negligible number of missing observations on income.

\subsubsection{Results}

To understand how the discontinuity in the age of household members at 65 years affects the vaccination decisions of a respondent, we conduct a probit analysis in which the dependent variable is a binary to indicate the respondent's vaccination status (Table 7). Controlling for socioeconomic conditions of the respondents as well as household characteristics, respondents who live in the same household as those aged 65 years and above are more likely to get vaccinated than are respondents who live with those aged under 65 years, indicating a peer effect in vaccination decisions. Specifically, the positive peer effect increases the probability of vaccination by $9.1 \%$. When controlling for household income, the magnitude of the coefficient

estimate decreases. Together with decreasing sample size in missing observations in income, the coefficient estimate is positive but no longer statistically significant. 
Next, we restrict our sample based on the age of household members to focus on the change at around 65 years. Ideally, we wish to examine how an individual would change his vaccination behavior right after his peer turns 65 years old and gets vaccinated. To increase the sample size, we slightly increase a bandwidth, and Column(2) of Table 7 shows the regression results based on respondents who live with those between 63 and 66 years old. The result is qualitatively consistent with the result of positive peer effects based on the entire sample, showing that the existence of those aged 65 years and above increases the probability of vaccination of a respondent. The magnitude of the coefficient is greater than the analysis based on the entire sample, which is likely due to the increased similarity in peers' characteristics between the two groups defined by peers' age. Again, the inclusion of household income as an independent variable reduces the magnitude of coefficient although the coefficient shows a positive sign.

Thus far, we find a positive effect on the probability of vaccination of having a member aged 65 years or above in the household. The peer effect, however, should occur owing to vaccination of the peer, not just the existence of a peer who has a greater incentive for vaccination compared to a counterpart in the control group. To examine if the probability of vaccination of household members indeed increases at the age of 65 years, we run a probit regression with a dataset that consists of only household members (2,539 household members). Specifically, we run a regression in which the vaccination status of each household member is the dependent variable and age, age squared, and the dummy variable indicate if the member is 65 years or older. As Table 8 demonstrates, the dummy variable for $65+$ indicates a positive and statistically significant effect on the probability of vaccination, increasing the probability of vaccination by 7.6 percentage points among household members. The effect increases when the analysis is restricted to those near the 65 -year cut-off point.

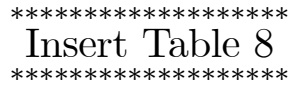




\subsubsection{Placebo test}

We find a positive peer effect in vaccination behavior by examining an exogenous change in financial incentives in vaccination due to the unique setting in the national immunization program in Japan. As the exogenous change occurs at the age of 65 years, we use the particular age as a cutoff point to handle the reflection problem. Next, we conduct a placebo test by using an alternative cutoff point to examine whether the effect is a real peer effect that occurred by a change in the incentives in vaccination uptake among peers. We show the results using two alternative cutoff points, 63 years and 70 years (Table 9). As expected, we do not observe a statistically significant effect of the change in the age among peers when we use 63 years as the cutoff point. By contrast, we observe a significant effect when we set 70 years as the cutoff point. This is likely due to the effect of increased vaccination among those aged 70 years or older, who constitute a part of the treatment group in the analysis.

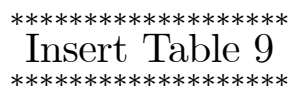

\section{Concluding remarks}

This study developed a voluntary provision model to formulate a vaccination game and to explain how the positive peer effect arises in deciding whether to vaccinate. This study empirically confirmed that a positive or conforming peer effect certainly exists. To the best of our knowledge, this study is the first to analyze the vaccination decisions of individuals using the voluntary provision model which is based on a utility-maximizing framework. Not only has this study enriched understanding of vaccination decisions, but it has also introduced a new approach that could considerably alter the standard modeling strategy for individuals' vaccination behavior as well as policy implications, in particular, for designing effective public health policy for preventing epidemics of infectious diseases and understanding interventions to improve vaccination coverage.

We obtain several novel and striking results in contrast to the previous literature. First, the simultaneous voluntary provision model of Warr (1983) and Bergstrom et al. (1986) is not 
consistent with a positive peer effect, because an individual does not have a chance of observing the past behavior of others in their static one-shot model; hence, one individual has to be a Stackelberg follower. Nevertheless, the sequential-move contribution model investigated by Varian (1994) reveals that the peer effect is always negative irrespective of the forms of utility functions or the supplying technology of public goods. As long as we use such a simple sequential-move model adopted by Varian, peer effects must be negative or non-conforming in the sense that individuals' vaccination decisions are inversely related to the group's decision. Second, we demonstrate that we can obtain a positive or conforming peer effect either when the desire for social status is included in the utility function of a contributor as a third additional factor, or when the conjectural variations model is endowed with the conjectural variation function, which depends positively on others' past contributions. Those additional ingredients play a critical role in generating a positive or conforming peer effect in such a way that the free-riding incentive of individuals is dominated by a counter-active effect caused by a third factor appearing in either the utility function or the conjectural variations function, such as the desire for social status, avoiding social stigma, gaining social prestige, or the social norm to conform, or bandwagon effect.

There are extensions to this research in several directions. First, the most natural next step is to empirically identify which model between the joint production and conjectural variations models discussed in this paper is more appropriate to explain a positive peer effect. Second, to derive a positive peer effect, it is assumed that in the voluntary provision models presented in this study, the average contribution or total provision of past donors is exogenously given. Relaxation of this assumption requires us to construct an explicit dynamic learning model for forming social norms over time to explain how people collect information and update their beliefs (i.e., the peer effect) about how the contributions of others respond to their own contributions before making their vaccination choices. The marriage between the voluntary provision model and an evolutionary game theory would pave the way for a new and promising analysis regarding individuals' vaccinating decisions. Although the theoretical as well as empirical analyses both would be very complicated, it deserves further study. Third, another interesting extension is to consider the network structure, because in reality, there is always a 
spatial structure on the transmission of information regarding who gets vaccinated and who each individual comes into contact with, as well as the overall structure of contact with other people. This extension would also be challenging for empirical studies. Fourth, the last interesting extension is to introduce a provision point discrete public good into the vaccination game or binary choices (see, e.g., Palfrey and Rosenthal, 1984) in which each individual can participate by making a fixed contribution; if a sufficient number of contributions are made or if the total provision exceeds some threshold level, the public good is provided, and otherwise not. This model would be very suitable for the description of individuals' vaccinating behavior (or the technology of supplying public goods) as well as the role of vaccination in preventing the spread of infectious diseases to other people.

\section{Appendix: Stability condition}

In this appendix, we show how to derive the stability condition for a Nash equilibrium in the model presented in Section 2. The best-reaction functions of both individuals are given by

$$
\begin{aligned}
& -u_{x}^{1}\left(\rho-g_{1}, G, Z_{1}\right)+u_{G}^{1}\left(\rho-g_{1}, G, Z_{1}\right)+u_{Z}^{1}\left(\rho-g_{1}, G, Z_{1}\right)=0, \\
& -u_{x}^{2}\left(\rho-g_{2}, G, Z_{2}\right)+u_{G}^{2}\left(\rho-g_{2}, G, Z_{2}\right)+u_{Z}^{2}\left(\rho-g_{2}, G, Z_{2}\right)=0,
\end{aligned}
$$

where $G=g_{1}+g_{2}$ and $Z_{i}=g_{i}-g_{j}, i, j=1,2 ; i \neq j$. Total differentiation of (A.1) and (A.2) and rearrangement results in

$$
\begin{aligned}
& \frac{d g_{2}}{d g_{1}}=-\frac{u_{x x}^{1}+u_{G G}^{1}+u_{Z Z}^{1}+2\left(u_{G Z}^{1}-u_{G x}^{1}-u_{Z x}^{1}\right)}{-u_{x G}^{1}+u_{G G}^{1}+u_{Z G}^{1}}<0, \\
& \frac{d g_{2}}{d g_{1}}=-\frac{-u_{x G}^{2}+u_{G G}^{2}+u_{Z G}^{2}}{u_{x x}^{2}+u_{G G}^{2}+u_{Z Z}^{2}+2\left(u_{G Z}^{2}-u_{G x}^{2}-u_{Z x}^{2}\right)}<0,
\end{aligned}
$$

where the best-reply functions of individuals 1 and 2 are given by $g_{1}=g_{1}\left(g_{2}\right)$ and $g_{2}=g_{2}\left(g_{1}\right)$, respectively, which implies that the slopes of both reaction functions are negative. 
For stability, the slopes of the best-reply functions should be ranked as follows:

$$
\left|\frac{d g_{2}}{d h_{1}}\right|_{1^{\prime} \text { s reaction }}>\left|\frac{d g_{2}}{d g_{1}}\right|_{2^{\prime} \text { s reaction }} .
$$

The inequality (A.3) can be rewritten as follows:

$$
\begin{aligned}
& \left|-\frac{u_{x x}^{1}+u_{G G}^{1}+u_{Z Z}^{1}+2\left(u_{G Z}^{1}-u_{G x}^{1}-u_{Z x}^{1}\right)}{-u_{x G}^{1}+u_{G G}^{1}+u_{Z G}^{1}}\right|_{1^{\prime} \text { s reaction }} \\
& >\left|-\frac{-u_{x G}^{2}+u_{G G}^{2}+u_{Z G}^{2}}{u_{x x}^{2}+u_{G G}^{2}+u_{Z Z}^{2}+2\left(u_{G Z}^{2}-u_{G x}^{2}-u_{Z x}^{2}\right)}\right|_{2^{\prime} \text { s reaction }},
\end{aligned}
$$

which is equivalent to

$$
\frac{u_{x x}^{1}+u_{G G}^{1}+u_{Z Z}^{1}+2\left(u_{G Z}^{1}-u_{G x}^{1}-u_{Z x}^{1}\right)}{-u_{x G}^{1}+u_{G G}^{1}+u_{Z G}^{1}}>\frac{-u_{x G}^{2}+u_{G G}^{2}+u_{Z G}^{2}}{u_{x x}^{2}+u_{G G}^{2}+u_{Z Z}^{2}+2\left(u_{G Z}^{2}-u_{G x}^{2}-u_{Z x}^{2}\right)},
$$

where the numerators of both sides are negative owing to the assumption of strict quasiconcavity. Moreover, (A.4) is equivalent to

$$
\begin{gathered}
{\left[u_{x x}^{1}+u_{G G}^{1}+u_{Z Z}^{1}+2\left(u_{G Z}^{1}-u_{G x}^{1}-u_{Z x}^{1}\right)\right]\left[u_{x x}^{2}+u_{G G}^{2}+u_{Z Z}^{2}+2\left(u_{G Z}^{2}-u_{G x}^{2}-u_{Z x}^{2}\right)\right]>} \\
\left(-u_{x G}^{1}+u_{G G}^{1}+u_{Z G}^{1}\right)\left(-u_{x G}^{2}+u_{G G}^{2}+u_{Z G}^{2}\right)
\end{gathered}
$$

which ensures that the sign of $|J|$ in (5) is positive.

\section{References}

Andreoni, J., 1990. "Impure altruism and donations to public goods: A theory of warm-glow giving", Econ. J. 100(401), 464-477.

Angrist, J.D., Lang, K., 2004. "Does school integration generate peer effects? Evidence from Boston's Metco program", Am. Econ. Rev. 94(5), 1613-1634.

Barrett, S., 2007 ."The smallpox eradication game", Public Choice 130(1/2), 179-207.

Bauch, C.T., Earn, D.J.D., 2004. "Vaccination and the theory of games", Proc. Natl. Acad. 
Sci. USA 101, 13391-13394.

Bauch, C.T., Galvani, A.P., Earn, D.J.D., 2003. "Group interest versus self-interest in smallpox vaccination policy", Proc. Natl. Acad. Sci. USA 100, 10564-10567.

Bauch, C.T., 2005. "Imitation dynamics predict vaccinating behaviour", Proc. Biol. Sci. 272, $1008-1015$.

Bergstrom, T., Blume, L., Varian, H.R., 1986. "On the private provision of public goods", J. Public Econ. 29, 25-49.

Bodine-Baron, E., Nowak, S., Varadavas, R., Sood, N., 2013. "Conforming and non-conforming peer effects in vaccination decisions", NBER Working Paper, No. 19528.

Chapman, G.B., Coups, E.J., 1999. "Time preferences and preventive health behavior: Acceptance of the influenza vaccine" Med. Decis. Mak. 19(3), 307-314.

Christaskis, N.A., Fowler, J.H., 2007. "The spread of obesity in a large social network over 32 years," New Engl. J. Med. 358, 2249-2258.

Clark, A.E., Loheac, Y., 2007. "It wasn't me, it was them!" Social influence in risky behavior by adolescent," J. Health Econ. 26, 763-784.

Cornes, R.C., Sandler, T., 1984a. "The theory of public goods: Non-Nash behavior," J. Public Econ. 23, 367-379.

Cornes, R.C., Sandler, T., 1984b. "Easy riders, joint production, and public goods," Econ. J. $94(375), 580-598$.

Dahl, G.B., Loslash, K., Katrine, V., Mogstad, M., 2014."Peer effects in program participation," Am. Econ. Rev. 104(7), 2049-2074.

Eisenberg, D., Golbertein, E., Whitlock, J.L., 2014. "Peer effects on risky behaviors: New evidence from college roommate assignments," J. Health Econ. 33, 126-138.

Evans, W.N., Oates, W.E., Schwab, R.M., 1992. "Measuring peer group effects: A study of teenager behavior," J. Political Econ. 100(5), 966-991. 
Fowler, J.H., Christaskis, N.A., 2008. "Estimating peer effects on health in social networks," J. Health Econ. 27(5), 1400-1405.

Gaviria, A., Raphael, S., 2001. "School-based peer effects and juvenile behavior," Rev. Econ. Stat. 83(2), 257-268.

Glazer, A., Konrad, K., 1996. "A signaling explanation for charity," Am. Econ. Rev. 86(4), $1019-1028$.

Hirshleifer, J., 1983. "From weakest-link to best-shot: The voluntary provision of public goods," Public Choice 41(3), 371-386.

Ibuka, Y., Li, M., Vietri, J.T., Chapman, G.B., Galvani, A.P., 2014. Free-riding behavior in vaccination decisions: An experimental study," PLoS One 9(1), 1-9.

Itaya,J., Dasgupta, D., 1995. "Dynamics, consistent conjectures, and heterogeneous agents in the private provision of public goods," Public Financ. 50, 371-389.

Kawaguchi, D., 2004. "Peer effects on substance use among American teenagers," J. Popul. Econ. 17(2), 351-367.

Khanna, J., Posnett, J., Sandler, T., 1995. "Charity donations in the UK: New evidence based on panel data," J. Public Econ. 56(2), 257-272.

Kingma, B.R., 1989. "An accurate measurement of the crowd-out effect, income effect, and price effect for charitable contributions," J. Political Econ. 97(5), 1197-1207.

Lundborg, P., 2006. "Having the wrong friends? Peer effects in adolescent substance use," J. Health Econ. 25, 214-233.

Manfredi, P., Posta, P.D., d'Onofrio, A., Salinelli, E., Centrone, F., Meo, C., Poletti, P., 2009. "Optimal vaccination choice, vaccination games, and rational exemption: An appraisal," Vaccine 28(1), 98-109.

Manski, C.F., 1993. "Identification of endogenous social effects: The reflection problem," Rev. Econ. Stud. 60(3), 531-542. 
Nuscheler, R., Roeder, K., 2015. "To vaccinate or to Procrastinate: That is the prevention question," Health Econ. 25(1), 1560-1581.

Palfrey, T.R., Rosenthal, H., 1984. "Partcipation and the provision of discrete public goods: Strategy analysis, J. Public Econ. 24, 171-193.

Powell, L.M., Tauras, J.A., Ross, H., 2005. "The importance of peer effects, cigarette prices and tobacco control policies for youth smoking behavior", J. Health Econ. 24, 950-968.

Rao, N., Kremer, M., Mobius, M., Rosenblat, T., 2017. Social Networks and Vaccination Decisions. Mimeo.

Romano, R., Yildirim, H., 2001. "Why charities announce donations: A positive perspective," J. Public Econ. 81, 423-447.

Sato, R., Takasaki, Y., 2016. "Peer effects on vaccination: Experimental evidence from rural Nigeria, " CIRJE Discussion Paper, CIRJE-F-1002.

Scafuri, A.J., 1988. "On consistency of conjectures in the private provision of public goods," J. Public Econ. 37, 395-398.

Sugden, R., 1985. "Consistent conjectures and voluntary contributions to public goods: Why the conventional theory doesn't work," J. Public Econ. 29, 117-124.

Trogdon, J.D., Nonnemaker, J., Pais, J., 2008. "Peer effects in adolescent overweight," J. Health Econ. 27, 1388-1399.

Varian, H.R., 1994. "Sequential contributions to public goods," J. Public Econ. 53, 165-186.

Warr, P., 1983. "The private provision of a public good is independent of the distribution of income," Econ. Lett. 13, 207-211. 
Table 1. Descriptive Statistics: Administrative data on influenza vaccination status of the elderly in Itoman city

\begin{tabular}{|c|c|c|c|c|c|}
\hline Variable & $\mathrm{N}$ & Mean & Std. Dev. & Min & Max \\
\hline Vaccination status $(\text { yes }=1)^{[b]}$ & 28,194 & 0.633 & n.a. & 0 & 1 \\
\hline \multicolumn{6}{|l|}{ Individual characteristics } \\
\hline Age & 28,194 & 75.58 & 7.871 & 59 & 107 \\
\hline Female $^{[b]}$ & 28,194 & 0.558 & n.a. & 0 & 1 \\
\hline \multicolumn{6}{|l|}{ Aza's characteristics } \\
\hline Mean proportion of vaccination & 28,194 & 0.633 & 0.077 & 0.1 & 1 \\
\hline Mean age & 28,194 & 75.58 & 1.861 & 65 & 83.35 \\
\hline Proportion of Female & 28,194 & 0.558 & 0.038 & 0 & 0.8 \\
\hline Population size & 28,194 & 313.9 & 159.2 & 1 & 785 \\
\hline Medical institution within $500 \mathrm{~m}$ & 28,194 & 0.781 & 1.377 & 0 & 6 \\
\hline $\begin{array}{l}\text { Family characteristics } \\
\qquad \text { Loss of a cohabiter (yes }=1)^{[b]}\end{array}$ & 17,714 & 0.121 & n.a. & 0 & 1 \\
\hline
\end{tabular}

${ }^{[b]}=$ binary variable. $n . a .=$ not applicable. 
Table 2. Peer effect in vaccination: community members as peer

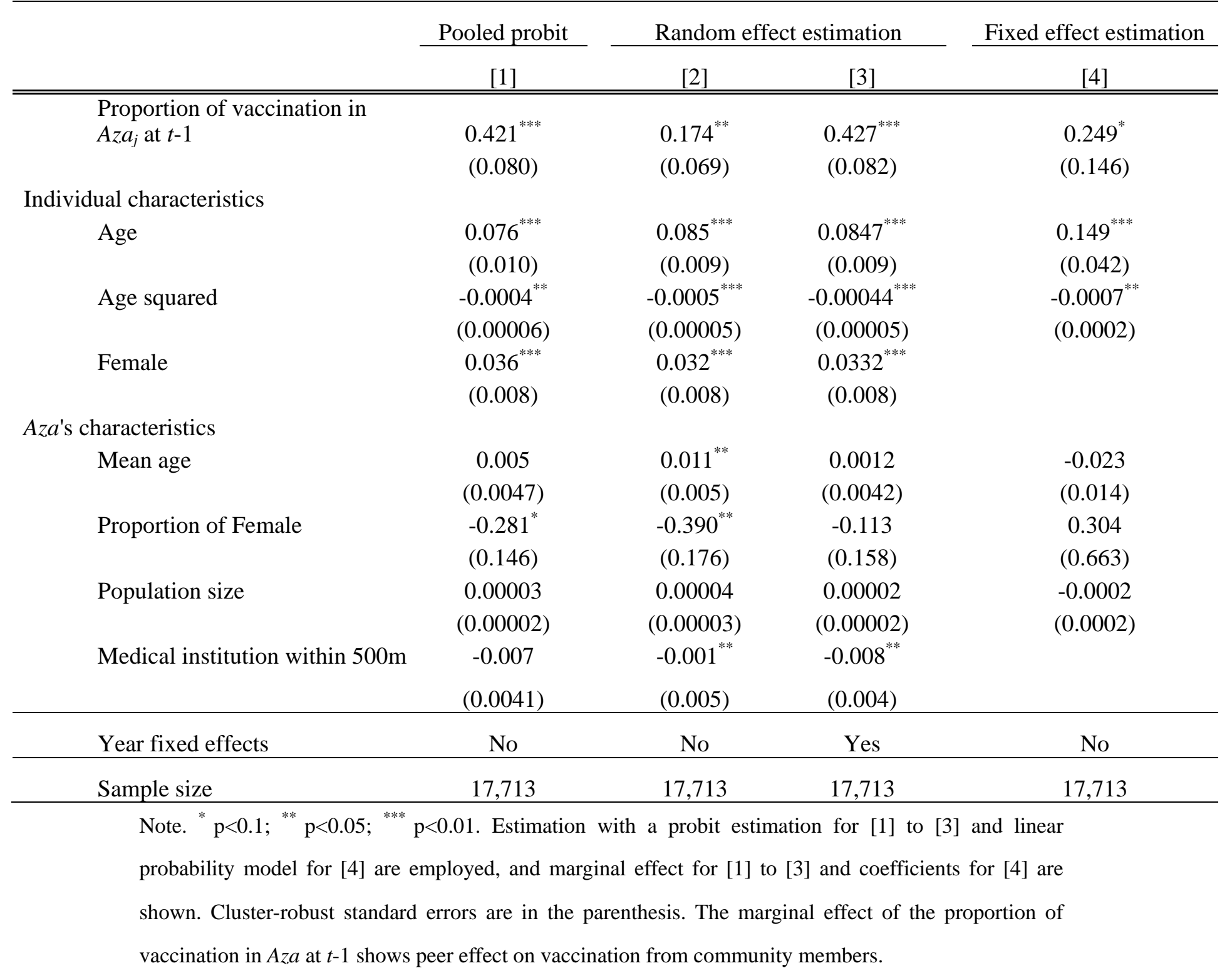


Table 3. Effect of loss of a cohabiter

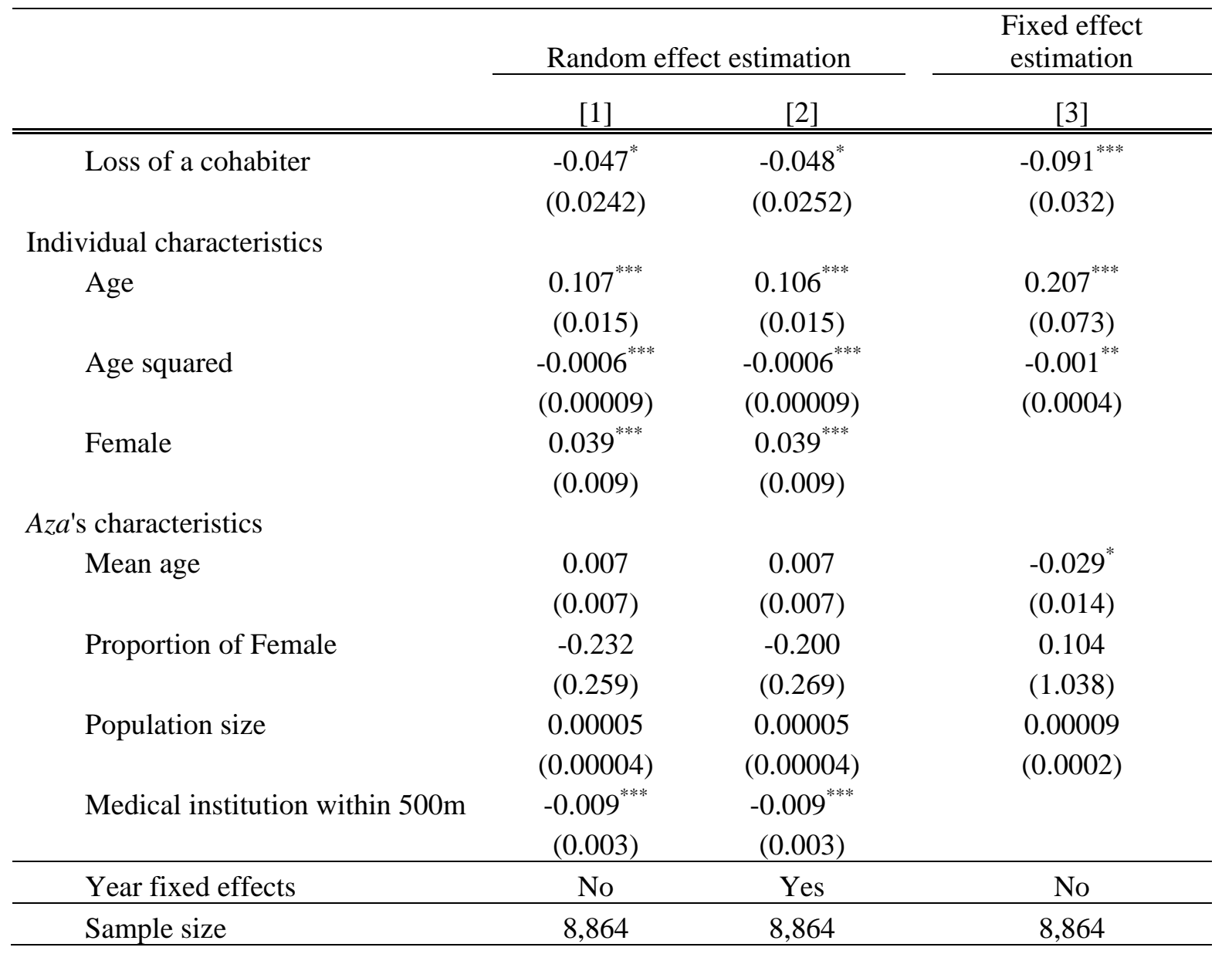

Note. ${ }^{*} \mathrm{p}<0.1 ;{ }^{* *} \mathrm{p}<0.05 ;{ }^{* * *} \mathrm{p}<0.01$. Estimation with the probit model for [1] and [2] and linear probability model for [3] are employed, and marginal effect for [1] and [2] and coefficients for [3] are shown. Cluster-robust standard errors are in the parenthesis. The coefficient of the loss of a cohabiter shows positive peer effect on vaccination from a cohabiter. 
Table 4. Effect of loss of a cohabiter who previously got vaccinated

\begin{tabular}{|c|c|c|c|}
\hline & \multicolumn{2}{|c|}{ Random effect estimation } & \multirow{2}{*}{$\begin{array}{c}\text { Fixed effect estimation } \\
{[3]} \\
\end{array}$} \\
\hline & {$[1]$} & [2] & \\
\hline Loss of household members & $\begin{array}{l}-0.081^{* * *} \\
(0.021)\end{array}$ & $\begin{array}{l}-0.081^{* * *} \\
(0.022)\end{array}$ & $\begin{array}{l}-0.083^{* *} \\
(0.032)\end{array}$ \\
\hline \multicolumn{4}{|l|}{ Individual characteristics } \\
\hline Age & $\begin{array}{l}0.076^{* * *} \\
(0.016)\end{array}$ & $\begin{array}{l}0.076^{* * *} \\
(0.016)\end{array}$ & $\begin{array}{l}0.166^{* *} \\
(0.080)\end{array}$ \\
\hline Age squared & $\begin{array}{l}-0.0004^{* * *} \\
(0.00009)\end{array}$ & $\begin{array}{l}-0.0004^{* * * *} \\
(0.00009)\end{array}$ & $\begin{array}{l}-0.001^{*} \\
(0.0005)\end{array}$ \\
\hline Female & $\begin{array}{l}0.031^{* * *} \\
(0.009)\end{array}$ & $\begin{array}{l}0.031^{* * *} \\
(0.009)\end{array}$ & \\
\hline \multicolumn{4}{|l|}{$A z a$ 's characteristics } \\
\hline Mean age & $\begin{array}{l}0.0008 \\
(0.004)\end{array}$ & $\begin{array}{l}0.0008 \\
(0.005)\end{array}$ & $\begin{array}{l}-0.042^{*} \\
(0.022)\end{array}$ \\
\hline Proportion of Female & $\begin{array}{c}0.224 \\
(0.195)\end{array}$ & $\begin{array}{c}0.220 \\
(0.212)\end{array}$ & $\begin{array}{c}0.363 \\
(1.039)\end{array}$ \\
\hline Population size & $\begin{array}{l}0.00008^{* * *} \\
(0.00002)\end{array}$ & $\begin{array}{l}0.00008^{* * *} \\
(0.00002)\end{array}$ & $\begin{array}{l}-0.0002 \\
(0.0002)\end{array}$ \\
\hline Medical institution within $500 \mathrm{~m}$ & $\begin{array}{l}-0.0006 \\
(0.004) \\
\end{array}$ & $\begin{array}{l}-0.0006 \\
(0.004) \\
\end{array}$ & \\
\hline Year fixed effects & No & Yes & No \\
\hline Sample size & 6,186 & 6,186 & 6,186 \\
\hline
\end{tabular}

Note: ${ }^{*} \mathrm{p}<0.1 ;{ }^{* *} \mathrm{p}<0.05 ;{ }^{* * *} \mathrm{p}<0.01$. Estimation with the probit model for [1] and [2] and linear probability model for [3] are employed, and marginal effect for [1] and [2] and coefficients for [3] are shown. Cluster-robust standard errors are in the parenthesis. The coefficient of the loss of a cohabiter shows positive peer effect on vaccination from a cohabiter. 
Table 5. Interaction of community peer effect and household peer effect

\begin{tabular}{|c|c|c|c|}
\hline & \multicolumn{2}{|c|}{ Random effect estimation } & \multirow{2}{*}{$\begin{array}{c}\begin{array}{c}\text { Fixed effect } \\
\text { estimation }\end{array} \\
{[3]} \\
\end{array}$} \\
\hline & [1] & [2] & \\
\hline Loss of a cohabiter & $\begin{array}{c}-0.300^{* *} \\
(0.146)\end{array}$ & $\begin{array}{c}-0.293 * * \\
(0.144)\end{array}$ & $\begin{array}{c}-0.725^{* * *} \\
(0.250)\end{array}$ \\
\hline Loss of a cohabiter x proportion of vaccination in $A z a_{j}$ at $t-1$ & $\begin{array}{c}0.350 \\
(0.230)\end{array}$ & $\begin{array}{c}0.334 \\
(0.228)\end{array}$ & $\begin{array}{c}1.028 * * \\
(0.396)\end{array}$ \\
\hline Proportion of vaccination in $A z a_{j}$ at $t-1$ & $\begin{array}{c}0.141 \\
(0.096)\end{array}$ & $\begin{array}{c}0.244 * * \\
(0.099) \\
\end{array}$ & $\begin{array}{c}0.218 \\
(0.222)\end{array}$ \\
\hline Year fixed effects & No & Yes & No \\
\hline Sample size & 6,186 & 6,180 & 6,186 \\
\hline
\end{tabular}

Note. ${ }^{*} \mathrm{p}<0.1 ;{ }^{* *} \mathrm{p}<0.05 ;{ }^{* * *} \mathrm{p}<0.01$. Estimation with the probit model for [1] and [2] and linear probability model for [3] are employed, and marginal effect for [1] and [2] and coefficients for [3] are shown. Cluster-robust standard errors are in the parenthesis. In all the regressions, individual and $A z a$ 's characteristics are controlled for using the same set of variables in Tables 2 to 4 . 
Table 6. Descriptive statistics: Survey data on vaccination status

\begin{tabular}{|c|c|c|c|c|c|}
\hline Variable & $\mathrm{N}$ & Mean & Std. Dev. & Min & $\operatorname{Max}$ \\
\hline Vaccination $(\text { yes }=1)^{[\mathrm{b}]}$ & 782 & 0.307 & n.a. & 0 & 1 \\
\hline $65+$ in $\mathrm{HH}(\mathrm{yes}=1)^{[\mathrm{b}]}$ & 782 & 0.478 & n.a. & 0 & 1 \\
\hline Sex & 782 & 1.596 & 0.491 & 1 & 2 \\
\hline Age & 782 & 46.07 & 13.34 & 19 & 64 \\
\hline Education: Less than high school diploma ${ }^{[b]}$ & 782 & 0.032 & n.a. & 0 & 1 \\
\hline Education: High school diploma ${ }^{[b]}$ & 782 & 0.385 & n.a. & 0 & 1 \\
\hline Education: College $\mathrm{e}^{[\mathrm{b}]}$ & 782 & 0.303 & n.a. & 0 & 1 \\
\hline Education: Associate degree ${ }^{[b]}$ & 782 & 0.254 & n.a. & 0 & 1 \\
\hline Education: Graduate level $^{[\mathrm{b}]}$ & 782 & 0.020 & n.a. & 0 & 1 \\
\hline Working (yes $=1)[\mathrm{b}]$ & 782 & 0.653 & 0.476 & 0 & 1 \\
\hline \# of flus shots in the past 5 years & 782 & 2.473 & 1.998 & 1 & 6 \\
\hline Self-rated health: Very good $^{[b]}$ & 782 & 0.101 & n.a. & 0 & 1 \\
\hline Self-rated health: Good ${ }^{[\mathrm{b}]}$ & 782 & 0.284 & n.a. & 0 & 1 \\
\hline Self-rated health: Fair ${ }^{[b]}$ & 782 & 0.486 & n.a. & 0 & 1 \\
\hline Self-rated heatlh: Poor $^{[b]}$ & 782 & 0.110 & n.a. & 0 & 1 \\
\hline Self-rated health: Very poor ${ }^{[b]}$ & 782 & 0.019 & n.a. & 0 & 1 \\
\hline Household size & 782 & 2.614 & 1.367 & 1 & 9 \\
\hline Child(ren) in HH $(\text { yes }=1)^{[\mathrm{b}]}$ & 782 & 0.083 & n.a. & 0 & 1 \\
\hline \# children in $\mathrm{HH}$ & 782 & 0.109 & 0.388 & 0 & 3 \\
\hline Maximum age of $\mathrm{HH}$ members & 782 & 67.53 & 9.637 & 2 & 98 \\
\hline Minimum age of $\mathrm{HH}$ members & 782 & 41.05 & 21.81 & 0 & 72 \\
\hline Average age of $\mathrm{HH}$ members & 782 & 54.45 & 12.59 & 2 & 80.33 \\
\hline Log of $\mathrm{HH}$ income & 591 & 4.765 & 4.187 & -9.210 & 8.006 \\
\hline Region 1: Hokkaido/Tohoku ${ }^{[b]}$ & 782 & 0.125 & n.a. & 0 & 1 \\
\hline Region 2: Kanto ${ }^{[b]}$ & 782 & 0.386 & n.a. & 0 & 1 \\
\hline Region 3: $\mathrm{Chubu}^{[\mathrm{b}]}$ & 782 & 0.162 & n.a. & 0 & 1 \\
\hline Region 4: Kinki ${ }^{[\mathrm{b}]}$ & 782 & 0.166 & n.a. & 0 & 1 \\
\hline Region 5: Chugoku ${ }^{[b]}$ & 782 & 0.054 & n.a. & 0 & 1 \\
\hline Region 6: Shikoku ${ }^{[\mathrm{b}]}$ & 782 & 0.028 & n.a. & 0 & 1 \\
\hline Region 7: Kyushu/Okinawa ${ }^{[b]}$ & 782 & 0.078 & n.a. & 0 & 1 \\
\hline
\end{tabular}

$[\mathrm{b}]=$ binary variable. n.a. $=$ not applicable $\mathrm{HH}=$ household 


\begin{tabular}{|c|c|c|c|c|}
\hline & \multicolumn{2}{|c|}{ All } & \multicolumn{2}{|c|}{$\begin{array}{l}\text { HH members aged } \\
\text { between } 63 \text { and } 66\end{array}$} \\
\hline & [1] & {$[2]$} & [3] & {$[4]$} \\
\hline HH member aged $65+$ years & $0.091^{*}$ & 0.065 & $0.125^{*}$ & 0.075 \\
\hline$($ yes $=1)$ & 0.052 & 0.059 & 0.07 & 0.059 \\
\hline \multirow[t]{2}{*}{ Sex } & 0.015 & 0.02 & 0.091 & $0.166^{* * *}$ \\
\hline & 0.046 & 0.051 & 0.077 & 0.059 \\
\hline \multirow[t]{2}{*}{ Age } & -0.02 & -0.015 & 0.007 & 0.024 \\
\hline & 0.018 & 0.023 & 0.025 & 0.022 \\
\hline \multirow[t]{2}{*}{ Age squared } & 0.000 & 0.000 & 0.000 & 0.000 \\
\hline & 0.000 & 0.000 & 0.000 & 0.000 \\
\hline \multirow[t]{2}{*}{ HH size } & -0.001 & 0.043 & -0.007 & 0.025 \\
\hline & 0.034 & 0.036 & 0.06 & 0.044 \\
\hline \multirow[t]{2}{*}{ Children under $6($ yes $=1)$} & 0.412 & $0.515^{*}$ & 0.075 & $-0.077^{*}$ \\
\hline & 0.272 & 0.291 & 0.437 & 0.044 \\
\hline \multirow[t]{2}{*}{ Number of children } & -0.15 & -0.246 & -0.118 & -0.16 \\
\hline & 0.141 & 0.165 & 0.238 & 0.141 \\
\hline Number of flu shots in the past 5 & $0.245^{* * *}$ & $0.246^{* * *}$ & $0.245^{* * *}$ & $0.194^{* * *}$ \\
\hline years & 0.021 & 0.025 & 0.033 & 0.056 \\
\hline \multirow[t]{2}{*}{ Log household income } & & -0.001 & & $-0.009^{*}$ \\
\hline & & 0.006 & & 0.005 \\
\hline Sample size & 782 & 591 & 322 & 245 \\
\hline
\end{tabular}


Table 8. Vaccination behavior of peer

\begin{tabular}{lll}
\hline & All sample & $\begin{array}{c}\text { HH members aged } \\
\text { between } 50 \text { and } 75 \text { years }\end{array}$ \\
\hline Dummy for $65+$ & $0.076^{* * * *}$ & $0.084^{* * *}$ \\
& $(0.029)$ & $(0.038)$ \\
Age & $-0.008^{* * *}$ & $-0.076^{* * *}$ \\
& $(0.002)$ & $(0.044)$ \\
Age squared & $0.00007^{* * *}$ & $0.0005^{* * *}$ \\
& $(0.00002)$ & $(0.0004)$ \\
\hline $\mathrm{N}$ & 2539 & 1433 \\
\hline Note. ${ }^{*} \mathrm{p}<0.1 ;{ }^{* *} \mathrm{p}<0.05 ;{ }^{* * *} \mathrm{p}<0.01$. The regression analysis & \\
household members of a survey respondent). &
\end{tabular}


Table 9. Placebo test

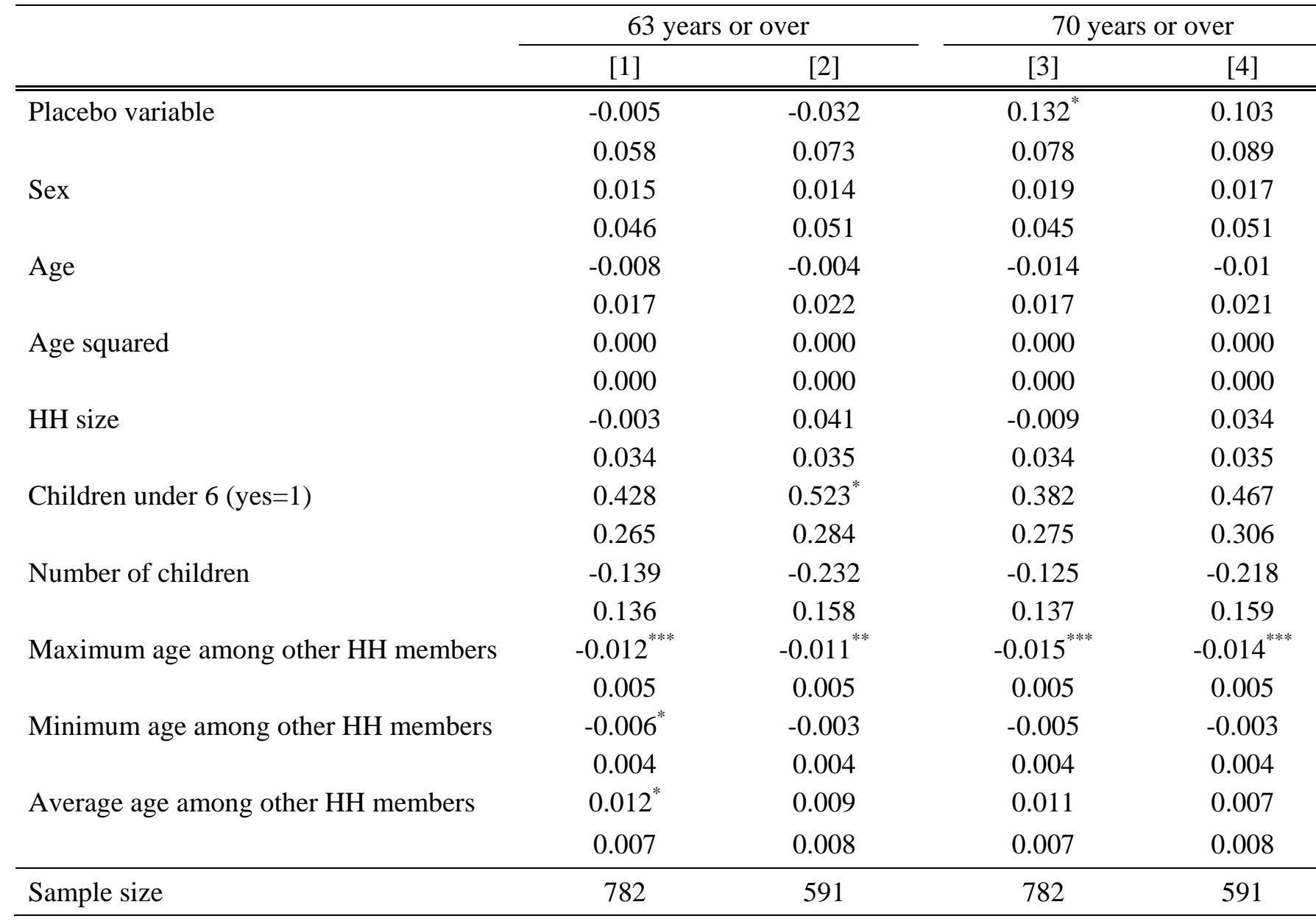

Note. ${ }^{*} \mathrm{p}<0.1 ;{ }^{* *} \mathrm{p}<0.05 ;{ }^{* * *} \mathrm{p}<0.01$. Marginal effects and standard errors in the parenthesis are shown. In all the regressions, household characteristics, education, working status, subjective health, and region are controlled for. 